\title{
Under temperate weather conditions, dairy goats use an outdoor run more with increasing warmth and avoid light wind or rain
}

\author{
Joanna Stachowicz, ${ }^{1,2 *}$ Anette Lanter, ${ }^{2}$ Lorenz Gygax, ${ }^{1,3}$ Edna Hillmann, ${ }^{2,3}$ Beat Wechsler, ${ }^{1}$ \\ and Nina Maria Keil ${ }^{1}$ \\ ${ }^{1}$ Centre for Proper Housing of Ruminants and Pigs, Federal Food Safety and Veterinary Office FSVO, Agroscope Tänikon, 8356 Ettenhausen, \\ Switzerland \\ ${ }^{2}$ ETH Zürich, Ethology and Animal Welfare Unit, Institute of Agricultural Sciences, 8092 Zürich, Switzerland \\ ${ }^{3}$ Animal Husbandry and Ethology, Albrecht Daniel Thaer-Institute of Agricultural and Horticultural Sciences, Humboldt Universität zu Berlin, \\ 10099 Berlin, Germany
}

\section{ABSTRACT}

Access to an outdoor run might provide some benefits for the social and activity behavior of dairy goats. The aim of this study was to investigate the influence of weather parameters on outdoor run use by dairy goats under temperate weather conditions. Data were collected from February to April and in October, 2014, on 14 commercial dairy goat farms in Switzerland and Germany for 14 d per farm. Temperature, humidity, solar radiation, wind speed, and rain amount were measured continuously using a weather station. The outcome variables, average proportion of the herd in the outdoor run (proportion of herd in run) and average frequency of goats entering the outdoor run per hour in relation to group size (frequency of entries to run), were assessed by video data. Temperature, humidity, and solar radiation were combined to create the parameter "warmth" by means of a principal component analysis, whereas wind speed and rain (rain events and rain amount) were used in their original form as explanatory variables. Additionally, the effect of the comprehensive climate index on outdoor run use was investigated. Data were analyzed using linear mixed effects models. Increasing "warmth" increased, whereas increasing wind speed reduced, the proportion of herd in run. With increasing comprehensive climate index, the proportion of herd in run and the frequency of entries to run increased. On days without rain, the proportion of herd in run and the frequency of entries to run were markedly higher than during comparable daytime hours with rain. In the hour before the rain started and after it had stopped, more goats were in the outdoor run than during rain hours, but still fewer than during comparable daytime hours on days

Received February 23, 2018.

Accepted October 7, 2018.

*Corresponding author: joa.stachowi@gmail.com without rain. Furthermore, the proportion of herd in run and the frequency of entries to run decreased to a very low level when the rain amount exceeded $1 \mathrm{~mm} / \mathrm{h}$. To conclude, in the measured ranges of temperature $\left(-0.8\right.$ to $\left.+16.5^{\circ} \mathrm{C}\right)$, humidity (34.8 to $\left.99.2 \%\right)$, solar radiation ( 25.9 to $519.8 \mathrm{~W} / \mathrm{m}^{2}$ ), and wind speed ( 0 to $4 \mathrm{~m} / \mathrm{s}$ ), warmer conditions increased the outdoor run use, whereas the goats clearly avoided light wind and rain. Therefore, in the outdoor runs, protection against rain and wind could promote their use under temperate weather conditions. Furthermore, ensuring optimized access to solar radiation by considering the exposure of the outdoor run might be of advantage, as direct sun exposure induces warmer conditions.

Key words: outdoor run use, dairy goat, weather parameter, comprehensive climate index, activity

\section{INTRODUCTION}

Access to an outdoor run can increase space allowance and could therefore positively affect lying behavior of goats (Andersen and Bøe, 2007). Moreover, an outdoor run provides visual cover by creating a physical separation between outdoors and indoors and may therefore serve as an area for retreat (Haskell et al., 2013). Finally, the outdoor run can offer the stimuli of the outside environment and can be equipped with various items, such as climbing opportunities, brushes, hayracks (Stachowicz et al., 2018), or branches (Bøe et al., 2012), to occupy the goats. It was demonstrated that goats used all the items provided when they were in the outdoor run (Bøe et al., 2012; Stachowicz et al., 2018). In this way, an outdoor run may promote speciesrelevant behaviors (Newberry, 1995; van de Weerd and Day, 2009). For example, Bøe et al. (2012) showed that goats were expressing play behavior in the outdoor run only. Provision of an outdoor run is required in regulations regarding organic farming in the European Union (Council Regulation, 1999) and Switzerland (Organic 
Farming Ordinance, 2015). Moreover, the Swiss government (Ordinance on Direct Payments, 2013) financially supports outdoor run access for goats.

Benefits of an outdoor run can only be achieved if the animals use it. The provision of enrichment items (Bøe et al., 2012), space, and structural elements were shown to positively influence outdoor run use in goats (Stachowicz et al., 2018). In temperate climate zones, goats might benefit from the outdoor run specifically during the winter feeding period. This is the period when, if access to pasture is given, goats are not put out to graze, due to little plant growth; it lasts approximately from October to May depending on latitude and altitude. During this time access to the outside environment is given via the outdoor run, if provided.

Because goats are regarded as being less tolerant to cold than sheep (Bøe and Ehrlenbruch, 2013), for example, weather conditions are likely to have an effect on outdoor run use during the winter feeding period. During this time, in temperate climate zones, temperatures are likely to reach the lower critical temperature of goats of approximately $9^{\circ} \mathrm{C}$ (Holmes and Moore, 1981). When the temperature falls into the range of the lower critical temperature, homeothermic animals have to increase their metabolic heat production substantially to maintain body core temperature ( $\mathrm{Lu}, 1989)$. However, whether thermal responses occur is determined by the interplay between temperature and other weather variables, such as wind, rain, humidity, and solar radiation. At low ambient temperatures, wind, rain, and humidity increase heat loss, whereas solar radiation reduces heat loss (Mader et al., 2010). Consequently, these climatic variables should be considered when assessing the effect of weather on animals. Depending on the research question, indices are often used to combine several climatic variables for analysis. For example, the comprehensive climate index (CCI) is a continuous index that adjusts temperature for the combined effects of humidity, solar radiation, and wind speed, with each parameter providing a correction for temperature in respect to their specific relationship. Hence, the CCI can be interpreted as the apparent temperature under a wide range of environmental conditions $\left(-30\right.$ to $+45^{\circ} \mathrm{C}$; Mader et al., 2010).

Responses to cold that have been observed in farm animals include huddling (sheep: Bøe, 1990; pigs: Hillmann et al., 2004), shivering (goats and sheep: Johnson, 1971), and changing the body posture to reduce the exposed body surface area (dairy cattle: Tucker et al., 2007). When animals can choose between outdoors and indoors, seeking shelter from adverse conditions is a most likely response. Charlton and Rutter (2017) found that cows spent less time in pasture and more indoors on rainy days and that their preference for pasture compared with being indoors varied with the season. Moreover, Krohn et al. (1992) reported that, in winter, cows preferred to lie indoors rather than in pasture. Regarding outdoor run use, Bøe and Ehrlenbruch (2013) found that dairy goats used the outdoor run less at temperatures below $0^{\circ} \mathrm{C}$ compared with temperatures above $0^{\circ} \mathrm{C}$ and less when it rained or snowed compared with phases without precipitation. However, studies considering the effect of several weather parameters measured on a continuous scale on outdoor run use by dairy goats are missing.

We therefore investigated outdoor run use by dairy goats under temperate weather conditions in relation to temperature, solar radiation, humidity, wind speed, and rain on 14 commercial farms during 2 winter feeding periods. We hypothesized that goats use an outdoor run more with increasing ambient temperature and solar radiation and less with increasing wind speed and humidity. Furthermore, we expected a decrease in outdoor run use during rain and more strongly with an increasing rain amount.

\section{MATERIALS AND METHODS}

\section{Animals and Housing}

Ethical approval to conduct the study was obtained from the Cantonal Veterinary Office, Frauenfeld, Thurgau, Switzerland (01/2014). The study was carried out between February and April and in October in 2014 on 11 Swiss and 3 German dairy goat farms $(\mathrm{n}=14$ in total). To reflect the variety of commercial dairy goat farms, the only inclusion criterion for the study was loose housing with direct access to an outdoor run. By using this approach, we increased the external validity of our study and made our results applicable for a variety of commercial farms similar in characteristics to the farms we used in the present study (Table 1). The pens were in closed buildings or in buildings with open fronts at 2 sides of the barn. Lying areas were all covered with straw for deep litter. The feeding place was either on a higher level than the lying area and with solid flooring or at the same level as the lying area and on deep litter with straw. The pens and the outdoor runs differed in space allowance, whether the outdoor runs were accessible via 1 or 2 entrances and whether the outdoor runs were partly covered by a roof, had wind breaks, or were oriented to 1 or 2 cardinal directions (meaning access to 1 or 2 sides along the building). Panels or wire fences surrounded the outdoor runs. Runs were accessible daily during the daytime hours or permanently. Roughage in the form of hay was fed restrictedly or ad libitum in the pen, though roughage was also accessible in the outdoor run at one 
farm. Concentrates were fed during milking only. Water was provided ad libitum on all farms. On each farm, 1 group of adult goats was observed. The animals were all $>1$ yr of age, and the age structure within groups was heterogeneous but relatively homogeneous between farms. The groups consisted of 1 breed, more than 1 breed, or crossbreeds. Group size ranged from 20 to 160 individuals, and groups differed in their horn status (Table 1).

\section{Data Collection}

Data were collected consecutively for $14 \mathrm{~d}$ per farm and on up to 3 farms simultaneously. Outdoor run use was recorded with a video camera (EverFocus EZ 930 with Infrared, EverFocus, Duarte, CA) placed above the entrance(s) to the outdoor run. This ensured accurate recording of the number of goats changing from indoors to outdoors and vice versa. However, due to technical problems with the camera and management procedures where the outdoor run had to be closed, only 3 to $13 \mathrm{~d}$ of video recording per farm were available (Tables 2 and 3). In addition, on each farm a commercial weather station (HOBO U30-NRC, Onset Computer Corp., Bourne, MA) was placed at a distance of 5 to $20 \mathrm{~m}$ from the outdoor run to record temperature $\left({ }^{\circ} \mathrm{C}\right)$, relative humidity $(\%)$, wind speed $(\mathrm{m} / \mathrm{s})$, solar radiation power $\left(\mathrm{W} / \mathrm{m}^{2}\right)$, and rain amount $(\mathrm{mm} / \mathrm{h})$, using a sampling rate of $2 \mathrm{~min}$. On each farm, data collection started 2 wk after the last goat kid had been separated from its mother, which occurred as a standard procedure on all farms around 1 to $2 \mathrm{~d}$ after birth. Consequently, the behavior of the goats was not affected by gestation or by the presence of their kids. The goats did not have access to pasture during the data collection period. On farms where more than one group of adults was available, one group was selected in which all individuals had finished kidding at least $2 \mathrm{wk}$ before the start of data collection.

To answer specific questions regarding outdoor run use and weather parameters, we extracted 2 data sets that were separate subsamples of the raw data collected. With one data set we examined the effect of temperature, humidity, solar radiation, and wind speed on outdoor run use at comparable times of day, whereas we tested the effect of rain on outdoor run use with the other data set.

\section{Data for Analyzing the Effects of Humidity, Solar Radiation, and Wind Speed}

To avoid excessive random variation due to daytime and to allow for a better comparison between farms, the first $2 \mathrm{~h}$ after feeding in the morning were chosen as the observation time. Because it rarely rained in these periods, only days without rain were included for analyzing the effect of temperature, humidity, solar radiation, and wind speed on outdoor run use ( 2 to $10 \mathrm{~d}$ per farm). Observations started after feeding when the first goat entered the outdoor run after being released from the feed line or after the re-opening of the outdoor run (depending on the farm) and ended $2 \mathrm{~h}$ later. Therefore, the exact time of day when observations started differed between farms due to management conditions (mean start time \pm SD: $0800 \mathrm{~h} \pm 0.88$ ). However, the observation periods were comparable in the sense that all goats were brought inside for milking and feeding and began to go out again afterward. Moreover, this period of day was generally the one with the highest outdoor run use (Stachowicz et al., 2018). Outdoor run use in terms of the "proportion of herd in run" and "frequency of entries to run" (see below) was calculated for these $2 \mathrm{~h}$ (Table 2).

To avoid redundancy (collinearity) among weather parameters due to high inter-correlation (Jolliffe, 2011), a principal component analysis was first performed. The first 2 principal components (PC1 52\% and PC2 26\%) explained a total of $78 \%$ of the variance. Temperature (loading 0.54), humidity (-0.62), and solar radiation $(0.12)$ loaded on PC1 and wind speed $(-0.95)$ loaded on PC2. The PC1 was therefore called "warmth," and "warmth" was used for further statistical analyses. Wind speed loaded on PC2 alone and was thus used for analysis based on its original values. Additionally, and to allow for better comparison with climatic conditions of other studies, the CCI (Mader et al., 2010) was used as a predictor variable.

\section{Data for Analyzing the Effect of Rain}

To determine the effect of rain on outdoor run use, we started out with the days per farm with rain ( 1 to $4 \mathrm{~d}$ per farm). On one farm, no rain occurred during the data recording period, and thus it was excluded from the analysis $(\mathrm{n}=13$ farms $)$. In addition, 3 to 4 d per farm were selected as control days. Control days were from the same farm with comparable values for temperature $\left(3.5\right.$ to $16.5^{\circ} \mathrm{C}$ ) and humidity (39 to $93 \%$ ), but without rain (for detailed sample size, see Table 3 ). On days with rain, we selected 2 -h periods, which included a change from dry hours to rain hours (start of rain; 20 occurrences) and vice versa (end of rain; 25 occurrences; Figure 1A), meaning it had rained in $1 \mathrm{~h}$ (Figure 1A; weather: rain) and been dry in the other (Figure 1A; weather: dry). The 2-h periods were selected within the daytime hours of outdoor run access between the morning feeding and start of evening milking and feeding (i.e., for a period of 6 to $12 \mathrm{~h}$ depending 
OUTDOOR RUN USE BY GOATS IN TEMPERATE WEATHER

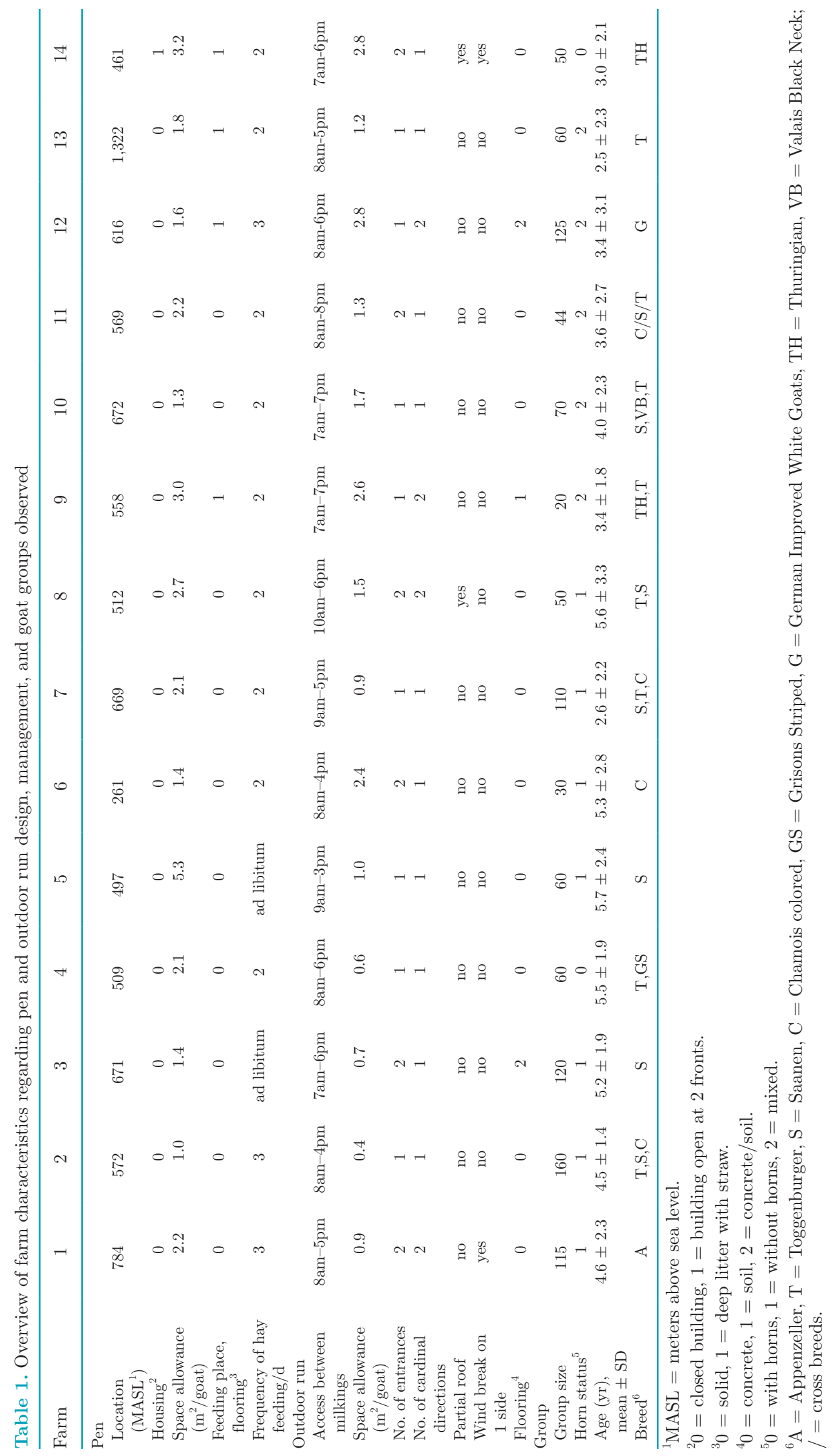




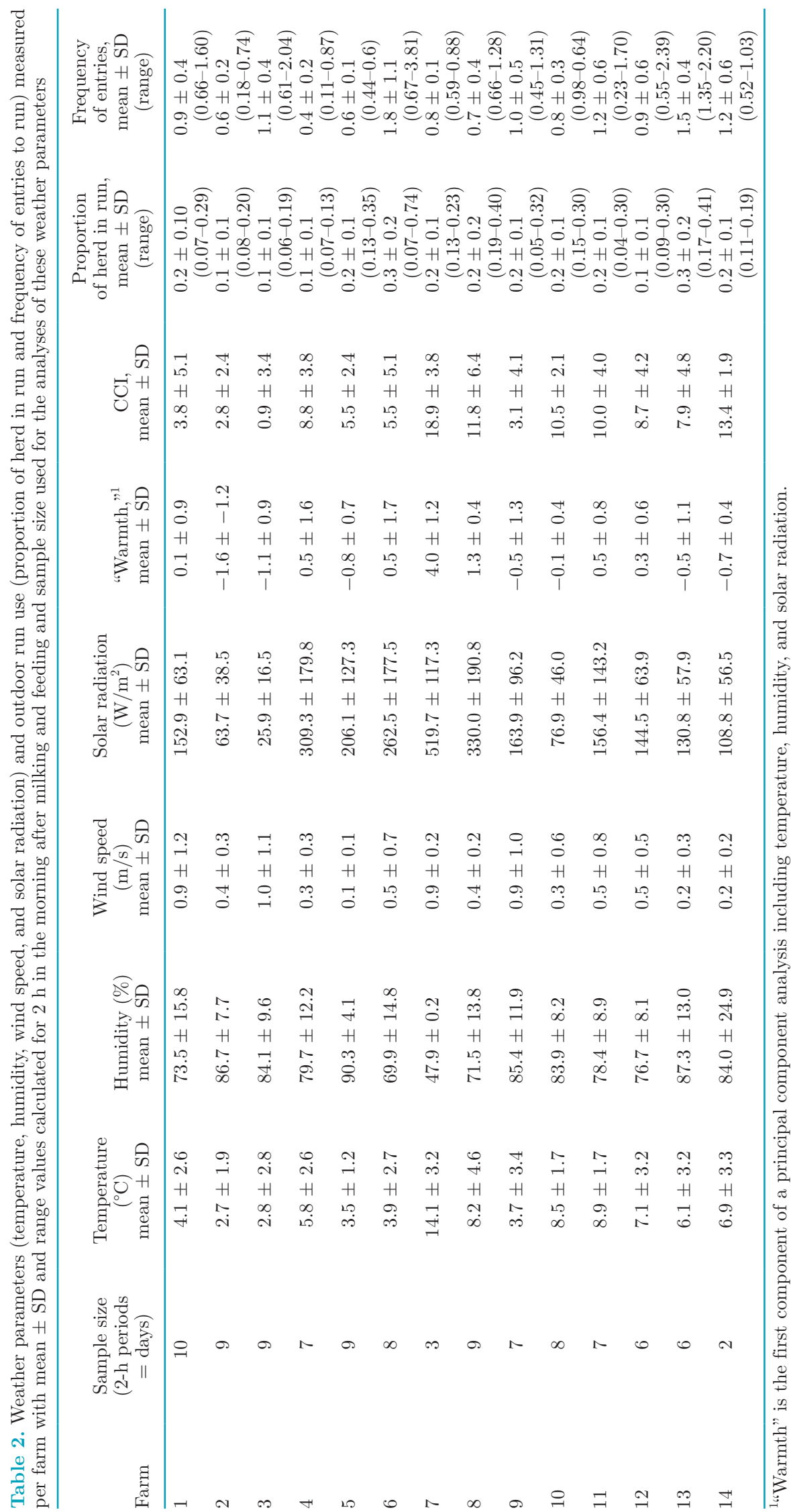


Table 3. Rain amount and outdoor run use (proportion of herd in run and frequency of entries to run) measured per farm with mean $\pm \mathrm{SD}$ and range values calculated for the rain hours of all rain events and sample size used for the analyses of the effect of rain

\begin{tabular}{|c|c|c|c|c|c|c|}
\hline \multirow[b]{2}{*}{ Farm } & \multicolumn{3}{|c|}{ Sample size } & \multirow{2}{*}{$\begin{array}{c}\text { Rain amount } \\
(\mathrm{mm}), \\
\text { mean } \pm \mathrm{SD}\end{array}$} & \multirow{2}{*}{$\begin{array}{l}\text { Proportion of } \\
\text { herd in run, } \\
\text { mean } \pm \mathrm{SD} \\
\quad \text { (range) }\end{array}$} & \multirow{2}{*}{$\begin{array}{c}\text { Frequency of } \\
\text { entries to run, } \\
\text { mean } \pm \mathrm{SD} \\
\text { (range) }\end{array}$} \\
\hline & $\begin{array}{l}\text { Rain } \\
\text { events }\end{array}$ & $\begin{array}{l}\text { Rain } \\
\text { days }\end{array}$ & $\begin{array}{c}\text { Control } \\
\text { days }\end{array}$ & & & \\
\hline 1 & 4 & 3 & 4 & $2.0 \pm 1.0$ & $\begin{array}{l}0.2 \pm 0.2 \\
\quad(0-0.06)\end{array}$ & $\begin{array}{l}0.0 \pm 0.0 \\
\quad(0-0.37)\end{array}$ \\
\hline 2 & 5 & 3 & 4 & $0.1 \pm 0.0$ & $\begin{array}{r}0.2 \pm 0.2 \\
\quad(0-0.03)\end{array}$ & $\begin{array}{r}0.0 \pm 0.0 \\
(0-0.44)\end{array}$ \\
\hline 3 & 7 & 4 & 4 & $2.7 \pm 1.7$ & $\begin{array}{r}0.4 \pm 0.6 \\
(0-0.34)\end{array}$ & $\begin{array}{c}0.1 \pm 0.1 \\
\quad(0-1.3)\end{array}$ \\
\hline 4 & 5 & 4 & 4 & $0.6 \pm 0.4$ & $\begin{array}{r}0.1 \pm 0.0 \\
(0-0.09)\end{array}$ & $\begin{array}{r}0.0 \pm 0.0 \\
(0-0.01)\end{array}$ \\
\hline 5 & 1 & 1 & 4 & $0.1 \pm 0.0$ & $\begin{array}{l}0.1 \pm 0.0 \\
\quad(0.007-0.007)\end{array}$ & $\begin{array}{l}0.0 \pm 0.0 \\
\quad(0.03-0.03)\end{array}$ \\
\hline 6 & 3 & 2 & 4 & $0.2 \pm 0.1$ & $\begin{array}{l}0.3 \pm 0.3 \\
\quad(0-0.12)\end{array}$ & $\begin{array}{l}0.1 \pm 0.1 \\
\quad(0-0.51)\end{array}$ \\
\hline 7 & - & - & - & - & - & - \\
\hline 8 & 3 & 3 & 4 & $1.1 \pm 0.5$ & $\begin{array}{l}0.4 \pm 0.4 \\
\quad(0.06-0.18)\end{array}$ & $\begin{array}{l}0.1 \pm 0.0 \\
\quad(0.17-0.92)\end{array}$ \\
\hline 9 & 7 & 3 & 4 & $0.1 \pm 0.0$ & $\begin{array}{l}0.3 \pm 0.3 \\
\quad(0.03-0.07)\end{array}$ & $\begin{array}{l}0.1 \pm 0.1 \\
\quad(0.16-0.41)\end{array}$ \\
\hline 10 & 2 & 2 & 4 & $1.1 \pm 0.3$ & $\begin{array}{l}0.5 \pm 0.3 \\
\quad(0.13-0.13)\end{array}$ & $\begin{array}{l}0.1 \pm 0.1 \\
\quad(1.08-1.08)\end{array}$ \\
\hline 11 & 1 & 1 & 4 & $0.1 \pm 0.0$ & $\begin{array}{l}0.3 \pm 0.1 \\
\quad(0-0.03)\end{array}$ & $\begin{array}{l}0.1 \pm 0.0 \\
\quad(0-0.33)\end{array}$ \\
\hline 12 & 5 & 3 & 4 & $0.9 \pm 0.5$ & $\begin{array}{l}0.3 \pm 0.4 \\
\quad(0.03-0.03)\end{array}$ & $\begin{array}{l}0.0 \pm 0.0 \\
\quad(0.31-0.31)\end{array}$ \\
\hline 13 & 1 & 1 & 4 & $0.8 \pm 0.0$ & $\begin{array}{l}0.3 \pm 0.0 \\
\quad(0.05-0.05)\end{array}$ & $\begin{array}{l}0.0 \pm 0.0 \\
\quad(0.14-0.14)\end{array}$ \\
\hline 14 & 1 & 1 & 3 & $0.6 \pm 0.0$ & $\begin{array}{l}0.2 \pm 0.0 \\
\quad(0.03-0.1)\end{array}$ & $\begin{array}{l}0.1 \pm 0.0 \\
\quad(0.09-0.82)\end{array}$ \\
\hline
\end{tabular}

on farm; Table 1). This time frame was chosen because, on some farms, the outdoor run was open only during daytime hours. To correct for the effect of time of day, 2 -h periods of the control days (without rain) at the same time of day were selected for each 2 -h period with rain (Figure 1B; control day). To allow comparison between the 2-h periods on days with and without rain, they were considered a rain event. More than one rain event could occur per day (Table 3). Outdoor run use in terms of "proportion of herd in run" and "frequency of entries to run" (see below) were calculated separately for each hour on each day ("observation time" $=1 \mathrm{~h}$ ). With the classification of weather, sequence, and day, we were able to compare outdoor run use between rain and dry hours (weather), between rain and dry hours of a different sequence (start of rain and end of rain), and between days with rain and days without rain at the corresponding dry and rain hours (day).

In addition, we investigated the effect of rain amount in millimeters per hour on outdoor run use. The amount of rain that had fallen during each rain hour of all considered rain events was used for this analysis ("observation time" = 1 h, 45 observations; Table 3 ).

\section{Outcome Variables of Outdoor Run Use}

Outdoor run use was calculated for the selected observation times ( $2 \mathrm{~h}$ for analyzing the effect of humidity, solar radiation, and wind speed and $1 \mathrm{~h}$ for analyzing the effect of rain; see previous sections) based on video recordings. The video recordings were analyzed each by one of 6 persons using the software ETHO (noncommercial video observation program; Weber, 2014). Interobserver reliability was not evaluated quantitatively, as the assessment of whether a goat enters or leaves the outdoor run provided little room for interpretation, and the results obtained were identical among observers. However, to check the accuracy of determining the change in the number of goats, the videos from $2 \mathrm{~d}$ from each person were randomly selected and $4 \mathrm{~h}$ of each day were analyzed a second time by a seventh person who found a high level of agreement.

The videos did not directly provide information on the number of goats in the outdoor run or in the pen (because the cameras were directed at the entries) and the goats could not be recognized individually. Therefore, to estimate outdoor run use, each exit or entry of 
a goat was continuously recorded as a change in the number of goats that were in the outdoor run (group level). A goat was registered as entering the outdoor run when all 4 feet were in the outdoor run. Correspondingly, a goat was noted as leaving the outdoor run when all 4 feet were no longer in the outdoor run. By using a continuous approach, we knew for how long a specific number of goats was in the outdoor run ("duration") and how often the outdoor run was entered ("number of entries").

From this data, we calculated 2 outcome variables, "proportion of herd in run" and "frequency of entries to run." As an average measure for the number of goats in the outdoor run, the following formula was used for "proportion of herd in run":

$$
\begin{aligned}
& \text { proportion of herd in run }= \\
& \frac{\Sigma(\text { no. of goats } \times \text { duration }) / \text { observation time }}{\text { group size }} .
\end{aligned}
$$

The number of goats in the outdoor run was weighted with the corresponding time during which this specific number of goats had stayed in the outdoor run (duration) and was summed up. The obtained value was then divided by the duration of the observation time $(2$ $\mathrm{h}$ for the effect of humidity, solar radiation, and wind speed or $1 \mathrm{~h}$ for the effect of rain; see previous sections). Additionally, the value was set in relation to the group size of a given farm, because the probability that more goats stay in the outdoor run should increase with increasing group size.
Reflecting the dynamic of outdoor run use, "frequency of entries to run" was estimated using the following formula:

$$
\begin{aligned}
& \text { frequency of entries to run }= \\
& \frac{\Sigma \text { no. of entries/observation time }}{\text { group size }} .
\end{aligned}
$$

The number of goats entering the outdoor run was summed up and divided by the duration of the observation time $(2 \mathrm{~h}$ for the effect of humidity, solar radiation, and wind speed or $1 \mathrm{~h}$ for the effect of rain) to obtain the average number of entries per hour. Again, because a higher probability for entries could be assumed with larger group sizes, the outcome variable was set in relation to group size.

\section{Statistical Analysis}

All statistical tests were conducted in R (version 3.2.4; R Development Core Team, 2015), using lmer to estimate mixed models (package lme4; Bates et al., 2015), PBmodcomp to calculate $P$-values for these mixed models (pbkrtest; Halekoh and Højsgaard, 2014), and boot for calculating model estimates and confidence intervals (boot; Canty and Ripley, 2015). Linear mixed effects models were chosen to account for dependencies in the data due to the experimental design (nesting and repeated measurements). Residuals of the data were plotted and visually inspected for normal distribution and homoscedasticity, and outcome variables were logit

rain event 1

rain event 2

$\begin{array}{rllllll}-1 & 0 & +1 & -1 & 0 & +1 & \text { time (h) }\end{array}$

A) day with rain

weather

sequence

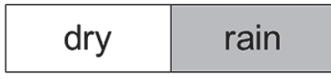

start of rain

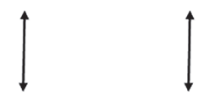

B) control day

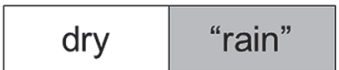

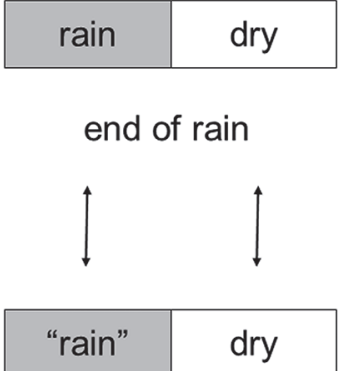

Figure 1. Graphical illustration for the analysis of rain events. On days with rain (A), rain events of 2-h durations were selected: $1 \mathrm{~h}$ with rain (weather: rain) and $1 \mathrm{~h}$ without rain (weather: dry), with rain either in the first hour (sequence: end of rain) or in the second hour (sequence: start of rain) of the rain event. For each day with rain, a control day without rain (B) was chosen. The daytime hours on the control days corresponded to the rain (indicated by quotes for control hours where it did not rain) and dry hours of the rain day, and were matched to the same rain event in the analysis. 
(proportion of herd in run) or log (frequency of entries to run) transformed to satisfy model assumptions. To facilitate transformation, values of 0 in the outcome variables were replaced by taking the minimum value greater than 0 of each outcome variable and subtracting $10 \%$ from this value.

For each of the 2 outcome variables ("proportion of herd in run" and "frequency of entries to run"), 4 models were calculated ( 8 in total). To assess the effect of humidity, solar radiation, and wind speed, 4 models were set up. In the first and second models, "warmth" and wind speed and their interaction were fitted as fixed effects and farm as a random effect. In the third and fourth models, the CCI was considered a fixed effect and farm as a random effect. To assess the effect of rain, the fifth and sixth models contained 3 fixed effects with 2 factor levels each: day (rain/control), weather (rain/dry), and sequence (end of rain/start of rain), their 2-way and the one 3-way interaction. The random effect in this model was day nested in rain event nested in farm. The seventh and eighth models contained the rain amount as fixed and farm as a random effect. The explanatory variables "warmth," wind speed, CCI, and rain amount were included in all models as continuous variables.

The final model was selected using the stepwise backward approach, starting with a full model and including all fixed effects and their interactions. To evaluate significance, $P$-values were calculated by parametric bootstrap test. Parametric bootstrap testing reduces the risk of type I error and better reflects the dependency of the data set (Halekoh and Højsgaard, 2014) and was therefore preferred over a likelihood ratio test. The critical $P$-value was set at a threshold of $P<0.05$.

\section{RESULTS}

\section{Effect of Temperature, Humidity, Solar Radiation, and Wind Speed}

Within the range of weather parameters measured (temperature: -0.8 to $+16.5^{\circ} \mathrm{C}$; humidity: 34.8 to $99.2 \%$; solar radiation: 25.9 to $519.8 \mathrm{~W} / \mathrm{m}^{2}$ : and wind speed: 0 to $4 \mathrm{~m} / \mathrm{s}$ ), we found that increasing "warmth" (higher solar radiation, higher temperature, and lower humidity) led to a higher proportion of herd in run (Figure 2A, "warmth"; $P<0.001$ ), whereas increasing wind speeds reduced the proportion of herd in run (Figure 2A, wind speed; $P<0.001$ ). We observed a positive relationship between the CCI and the proportion of herd in run (Figure 2B; $P<0.001$ ).

"Warmth" and wind speed interacted with the frequency of entries to run (Figure 3A; $P=0.02$ ). At lower wind speeds, the frequency of entries to the run increased slightly with increasing "warmth," but at higher wind speeds, the frequency of entries to run decreased with increasing "warmth." The CCI was positively associated with the frequency of entries to run (Figure 3B; $P=0.029$ ). For all the models, the variability in outdoor run use between farms was on a much lower level than the variability between the days (residuals; Table 4).

\section{Effect of Rain}

We found an interaction between day and weather on the proportion of herd in run (Figure 4A; $P<0.001$ ). On days with rain, the proportion of herd in run was smaller than on control days. Furthermore, on days with rain, the proportion of herd in run was smaller during rain hours than during dry hours, whereas this proportion did not differ between the "rain" and dry hours on control days (without rain). The variability in proportion of herd in run was small between rain events and farms, whereas it was high between days and hours (residuals; Table 5). Rain amount negatively affected the proportion of herd in run (Figure 4B; $P=$ 0.025 ), and the variability between farms was substantially lower than the variability between days (residuals; Table 5).

Day and weather interacted with the frequency of entries to run (Figure 5A; $P<0.001$ ) with the same pattern as described above for the proportion of herd in run. In addition, we observed an effect of the interaction of weather and sequence on the frequency of entries to run (Figure 5A; $P<0.01$ ). On days with rain, the frequency of entries to run decreased from dry to rain hours (Figure 5A, sequence: start of rain) and increased from rain to dry hours (Figure 5A, sequence: end of rain). On control days, the frequency of entries to run decreased from the first to the second hour (both in the sequence start of rain and in the sequence end of rain). The variability in frequency of entries to run was small between rain events and farms, whereas it was high between days and hours (residuals; Table 5). Rain amount negatively affected the frequency of entries to run (Figure 5B; $P=0.011$ ) and the variability between farms was substantially lower than the variability between days (residuals; Table 5).

\section{DISCUSSION}

We conducted a study on outdoor run use by goats in loose housing on commercial dairy farms in relation to weather conditions during the winter feeding period. The results show that the goats avoided wind and rain and used an outdoor run more under warmer, rather than colder, conditions. 


\section{CCl, "Warmth," and Wind Speed}

Based on the variable "warmth," a principal component combining temperature, humidity, and solar radiation, as well as with the CCI that additionally adjusts for wind speed, we showed that warmer conditions led to an increase in outdoor run use. In previous studies, goats spent more time in the outdoor run at ambient temperatures above $0^{\circ} \mathrm{C}$ than at temperatures below $0^{\circ} \mathrm{C}$ (Bøe and Ehrlenbruch, 2013). Furthermore, goats reduced their lying time by about $10 \%$ at ambient temperatures between -6 and $-12^{\circ} \mathrm{C}$, compared +10 and $+12^{\circ} \mathrm{C}$ (Bøe et al., 2007). The temperature range analyzed in the present study $\left(-0.8\right.$ to $+16^{\circ} \mathrm{C}$, with a mean of $+5.0^{\circ} \mathrm{C}$ ) was higher in comparison to those studies. However, we still observed that outdoor run use con- tinuously increased with increasing "warmth" and CCI. A possible explanation is that our temperature range was still below the upper critical temperature for goats, which ranges from 25 to $30^{\circ} \mathrm{C}$ (Lu, 1989), but included the lower critical temperature of $9^{\circ} \mathrm{C}$ determined for feral goats with a coat length of $57 \mathrm{~mm}$ (Holmes and Moore, 1981). Because high-producing animals have a higher metabolic heat production (Kadzere et al., 2002), one could expect that sub-adult and nonlactating dairy goats would presumably show a reduction in outdoor run use at higher temperatures than would the lactating individuals in our study.

By analyzing the effect of wind and "warmth" separately, we could show that the goats clearly avoided even very weak wind. However, the pattern for frequency of entries to run showed a reverse relationship

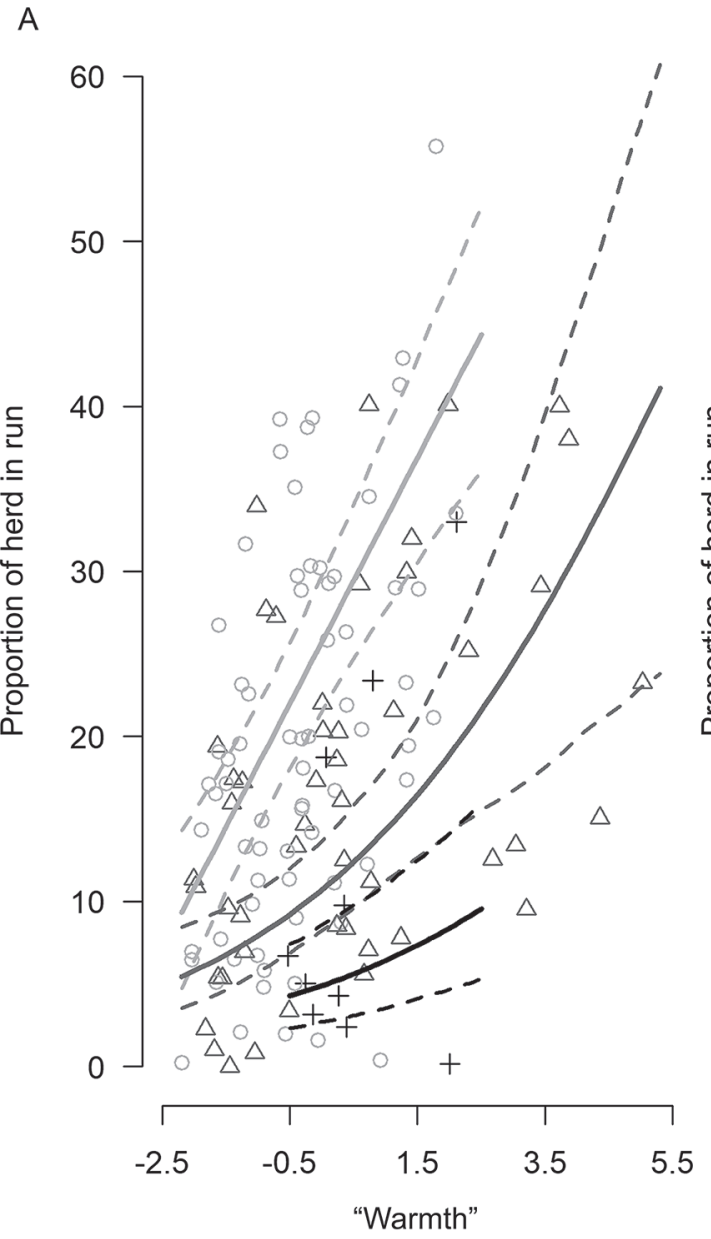

B

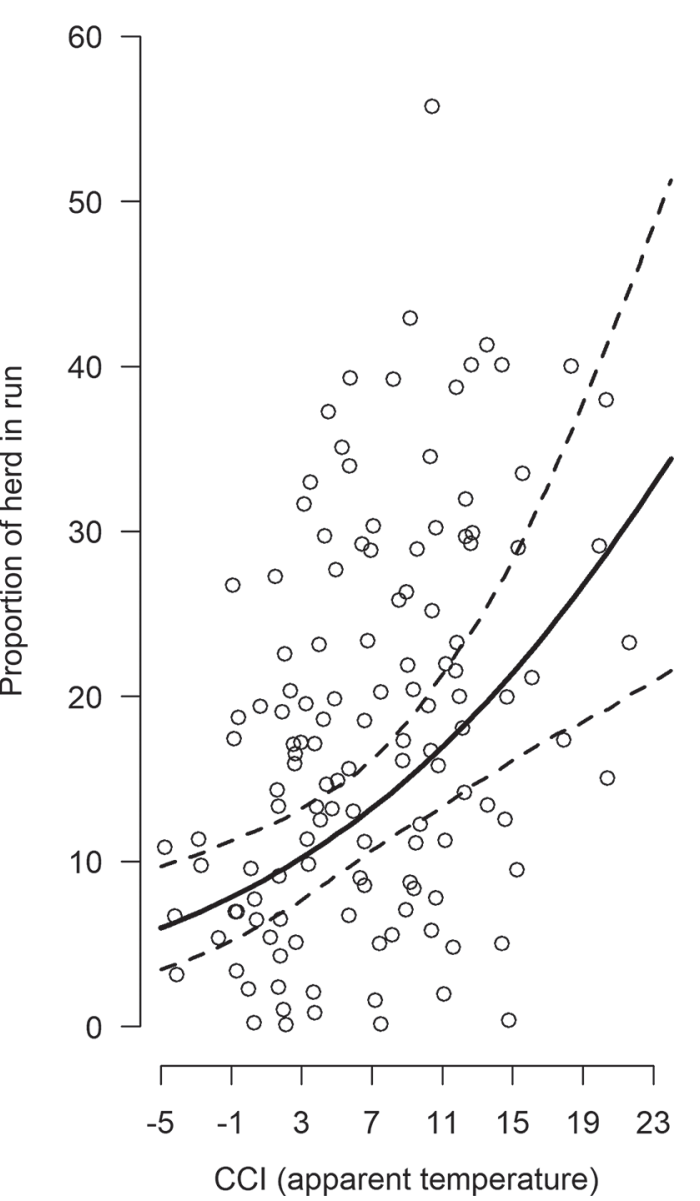

Figure 2. Proportion of herd in run in relation to "warmth" and wind speed (A) and to comprehensive climate index (CCI; B) during 2 observation hours per day after feeding and milking in the morning. "Warmth" is the first component of a principal component analysis including temperature, humidity, and solar radiation. Lines: solid $=$ model estimates and dashed $=95 \%$ CI. Wind speed was analyzed as a continuous variable; however, for graphical illustration, specific values for wind speed were used to divide wind into 3 categories. In $\mathrm{A}$, the $\mathrm{O}$ symbols represent the lowest wind category with wind speeds from $>0$ to $<0.3 \mathrm{~m} / \mathrm{s}$ and a model estimate in light gray. The $\Delta$ symbols represent the medium wind category including wind speeds from $\geq 0.3$ to $<1.6 \mathrm{~m} / \mathrm{s}$ and a model estimate in gray. The + symbols represent the strongest wind category with wind speeds from $\geq 1.6$ to $\leq 4 \mathrm{~m} / \mathrm{s}$ and a model estimate in black. 
A

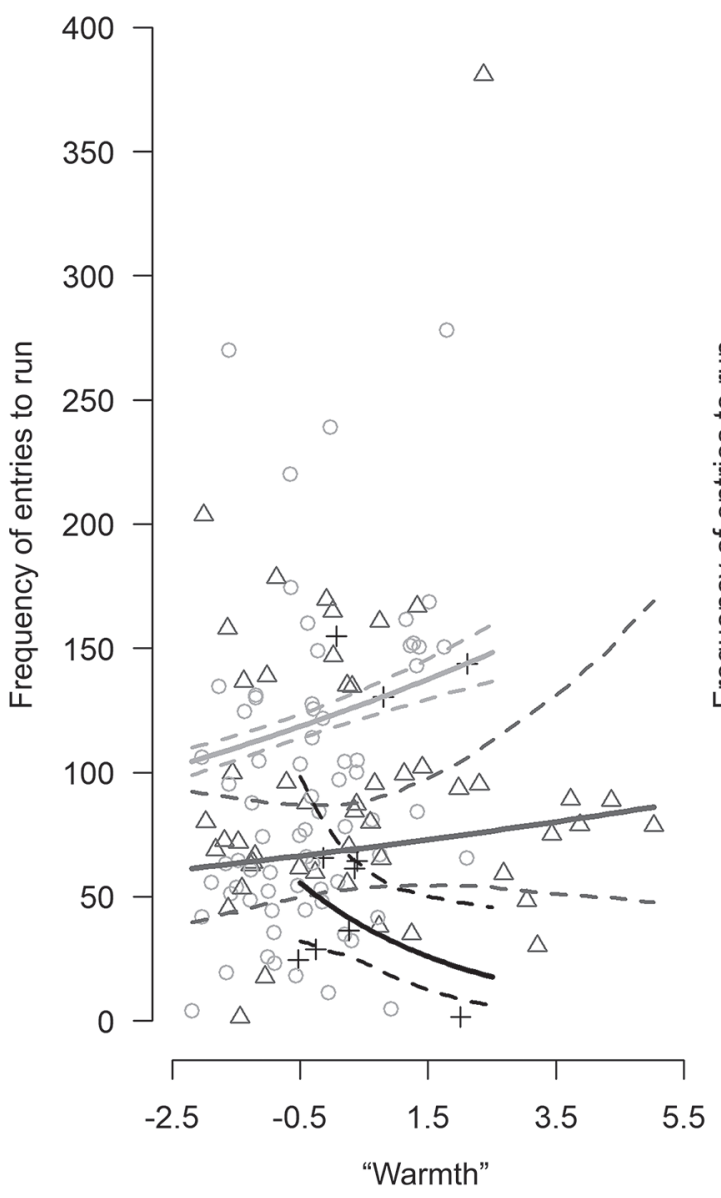

B

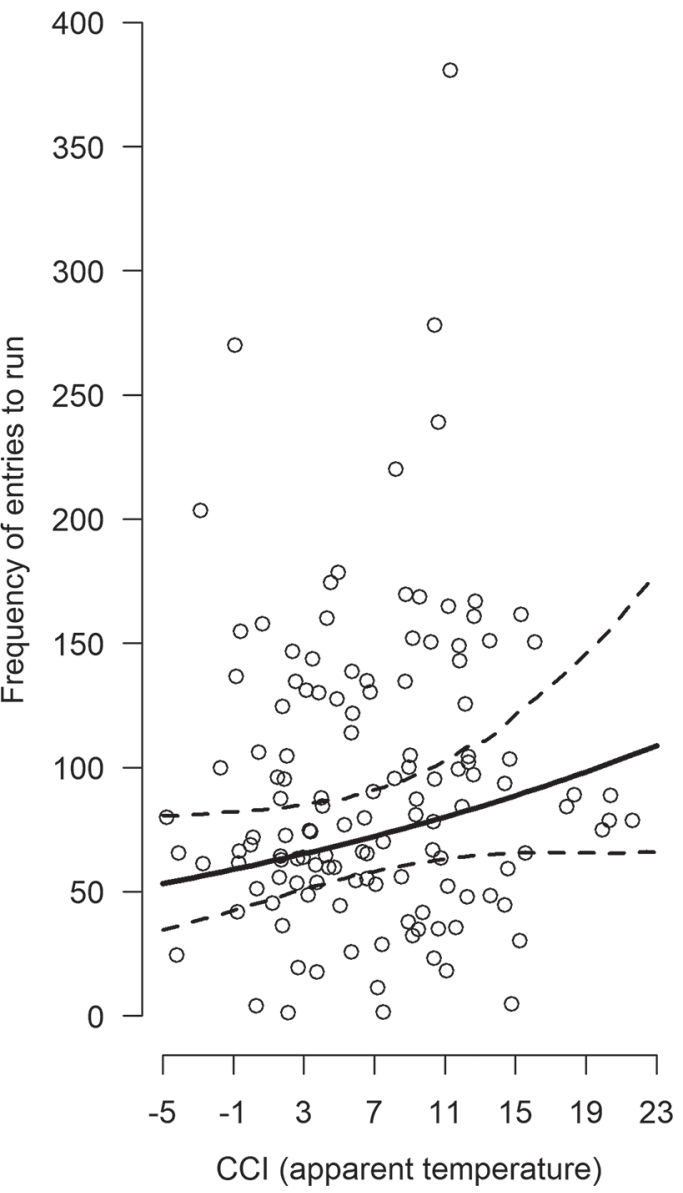

Figure 3. Frequency of entries to run in relation to "warmth" and wind speed (A) and to comprehensive climate index (CCI; B) during 2 observation hours per day in the morning after feeding and milking. "Warmth" is the first component of a principal component analysis including temperature, humidity, and solar radiation. Lines: solid $=$ model estimates and dashed $=95 \%$ CI. Wind speed was analyzed as a continuous variable; however, for graphical illustration, specific values for wind speed were used to divide wind into 3 categories. In $\mathrm{A}$, the $\mathrm{O}$ symbols represent the lowest wind category with wind speeds from $>0$ to $<0.3 \mathrm{~m} / \mathrm{s}$ and a model estimate in light gray. The $\Delta$ symbols represent the medium wind category including wind speeds from $\geq 0.3$ to $<1.6 \mathrm{~m} / \mathrm{s}$ and a model estimate in gray. The + symbols represent the strongest wind category with wind speeds from $\geq 1.6$ to $\leq 4 \mathrm{~m} / \mathrm{s}$ and a model estimate in black.

for "warmth" with the highest wind category compared with the other 2 lower wind categories, which is also in contrast to the results of proportion of herd in run.
However, by measuring how often an outdoor run is entered and left, short-term actions that occur during the day include those related to weather conditions as

Table 4. Variance of the random effects on the transformed scale of the model's "warmth" and wind, and comprehensive climate index (CCI), respectively, for both outcome variables (proportion of herd in run and frequency of entries to run $)^{1}$

\begin{tabular}{llcc}
\hline & & \multicolumn{2}{c}{ Variance random effects } \\
\cline { 3 - 4 } Outcome variable & Final model & $\begin{array}{c}\text { Farm, } \\
\text { mean } \pm \text { SD }\end{array}$ & $\begin{array}{c}\text { Day (= residual), } \\
\text { mean } \pm \text { SD }\end{array}$ \\
\hline Proportion of herd in run & "Warmth" + wind & $0.1 \pm 0.3$ & $1.2 \pm 1.9$ \\
Frequency of entries to run & CCI & $0.1 \pm 0.2$ & $1.3 \pm 1.2$ \\
& "Warmth" $\times$ wind & $0.1 \pm 0.4$ & $0.5 \pm 0.7$ \\
& CCI & $0.1 \pm 0.4$ & $0.2 \pm 0.5$ \\
\hline
\end{tabular}

"Warmth" is the first component of a principal component analysis including temperature, humidity, and solar radiation. The CCI adjusted temperature for the combined effect of solar radiation, humidity, and wind speed and can be interpreted as the apparent temperature under a wide range of environmental conditions. 
Table 5. Variance of the random effects on the transformed scale of the models for rain and rain amount, respectively, for both outcome variables (proportion of herd in run and frequency of entries to run)

\begin{tabular}{|c|c|c|c|c|c|}
\hline Outcome variable & Final model & $\begin{array}{l}\text { Farm, } \\
\text { mean } \pm \mathrm{SD}\end{array}$ & $\begin{array}{l}\text { Rain event, } \\
\text { mean } \pm \text { SD }\end{array}$ & $\begin{array}{c}\text { Day, } \\
\text { mean } \pm \mathrm{SD}\end{array}$ & $\begin{array}{c}\text { Hour } \\
(=\text { residual }) \\
\text { mean } \pm \mathrm{SD}\end{array}$ \\
\hline Proportion of herd in run & Day $^{1} \times$ weather $^{2}$ & $0.3 \pm 0.5$ & $0.1 \pm 0.3$ & $0.8 \pm 0.9$ & $0.4 \pm 0.6$ \\
\hline Frequency of entries to run & $\begin{array}{l}\text { Rain amount } \\
\text { Day }{ }^{1} \times \text { weather }^{2}+\text { sequence }^{3} \times \text { weather }^{2} \\
\text { Rain amount }\end{array}$ & $\begin{array}{l}0.2 \pm 0.5 \\
0.2 \pm 0.4 \\
0.0 \pm 0.2\end{array}$ & $0.1 \pm 0.4$ & $0.9 \pm 0.9$ & $\begin{array}{l}2.0 \pm 1.4 \\
0.7 \pm 0.8 \\
2.5 \pm 1.6\end{array}$ \\
\hline
\end{tabular}

${ }^{1}$ Factor with 2 levels: day with rain, day without rain.

${ }^{2}$ Factor with 2 levels: dry, rain.

${ }^{3}$ Factor with 2 levels: start of rain, end of rain.

${ }^{4}$ Continuous variable: amount of rain $(\mathrm{mm})$ per hour.

well as actions due to social events (Haskell et al., 2013) or management. This condition might limit the suitability of this variable for measuring outdoor run use in relation to weather conditions.
The maximal wind speed of $4 \mathrm{~m} / \mathrm{s}$ and the mean wind speed of $0.5 \mathrm{~m} / \mathrm{s}$ measured in our study are equal to the wind categories 3 and 0 out of 5 , respectively, on the Beaufort wind scale and are defined as "light

A

B
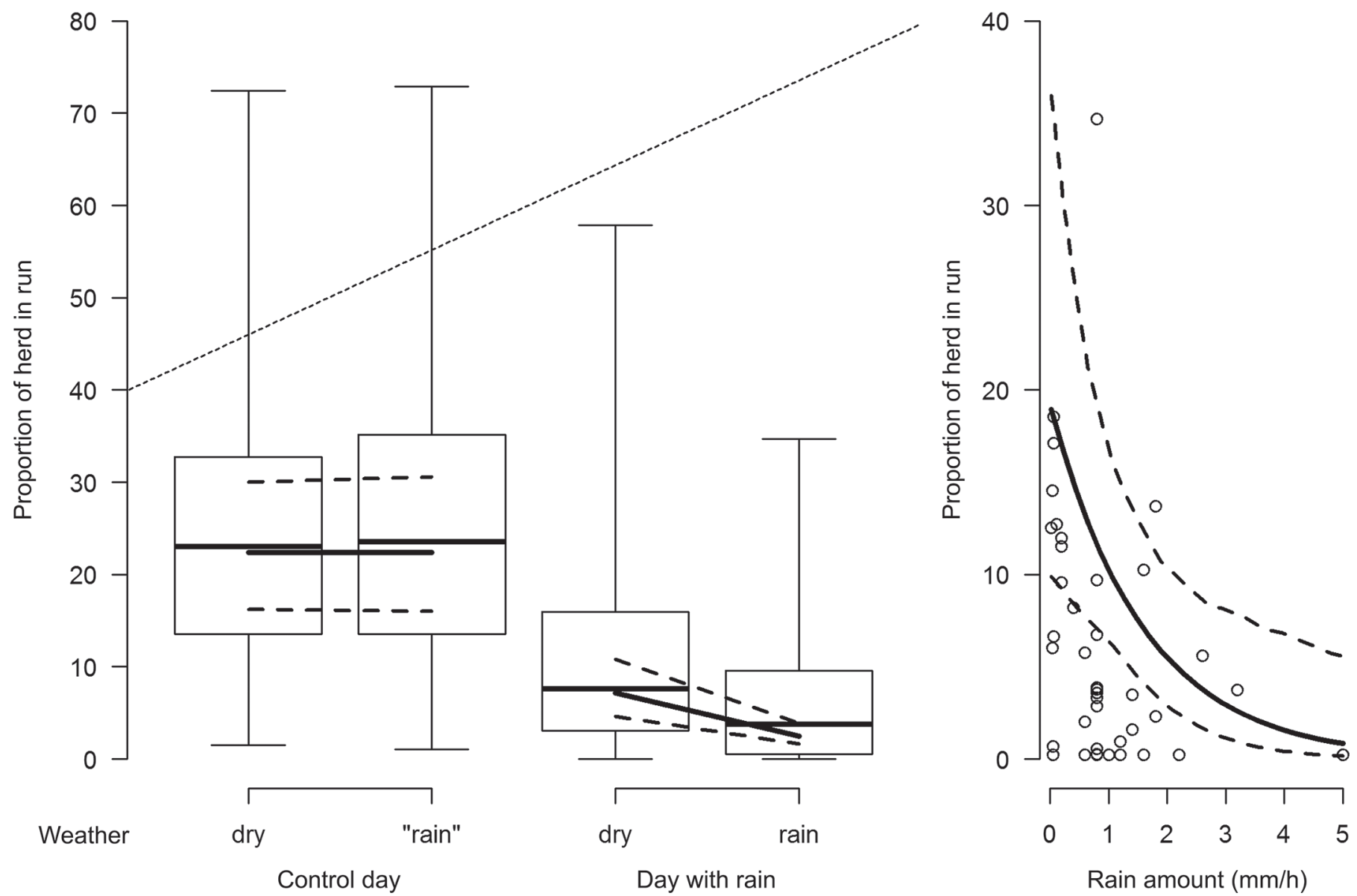

Figure 4. Proportion of herd in run in relation to day (rain/control) and weather (dry/rain) during the 2-h phases (A). The dry and "rain" hours of control days correspond to the dry and rain hours of rain days at the same time of day. On control days, it never rained (indicated by quotation marks). Proportion of herd in run in relation to rain amount per hour (B). The y-axis in B is a section of the y-axis in A and refers to the rain hour on a rainy day (diagonal line). Boxplots: mid line $=$ median; boxes $=$ interquartile ranges; and whiskers $=$ absolute ranges. Lines: solid $=$ model estimates and dashed $=95 \%$ CI. 
A

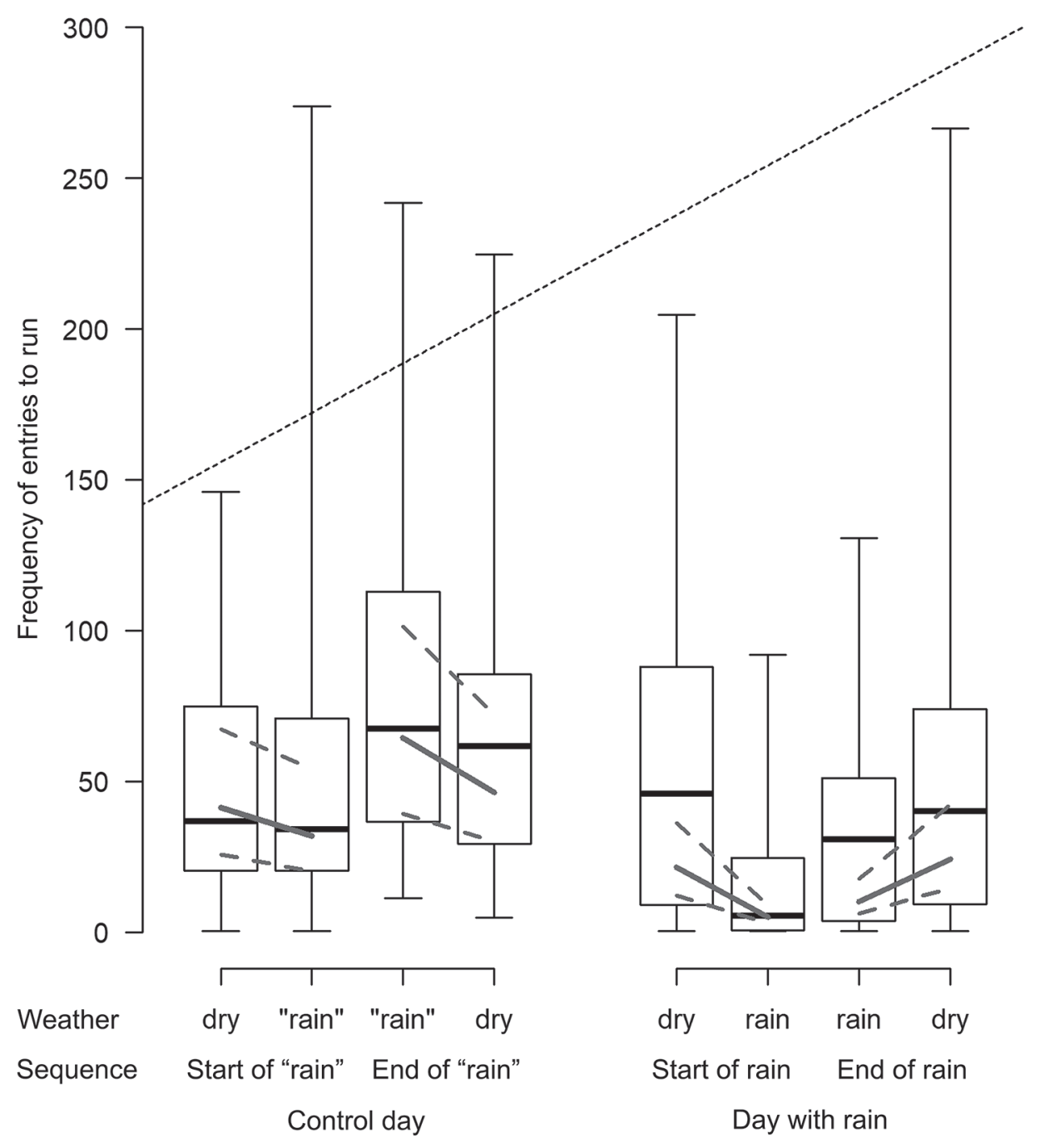

B

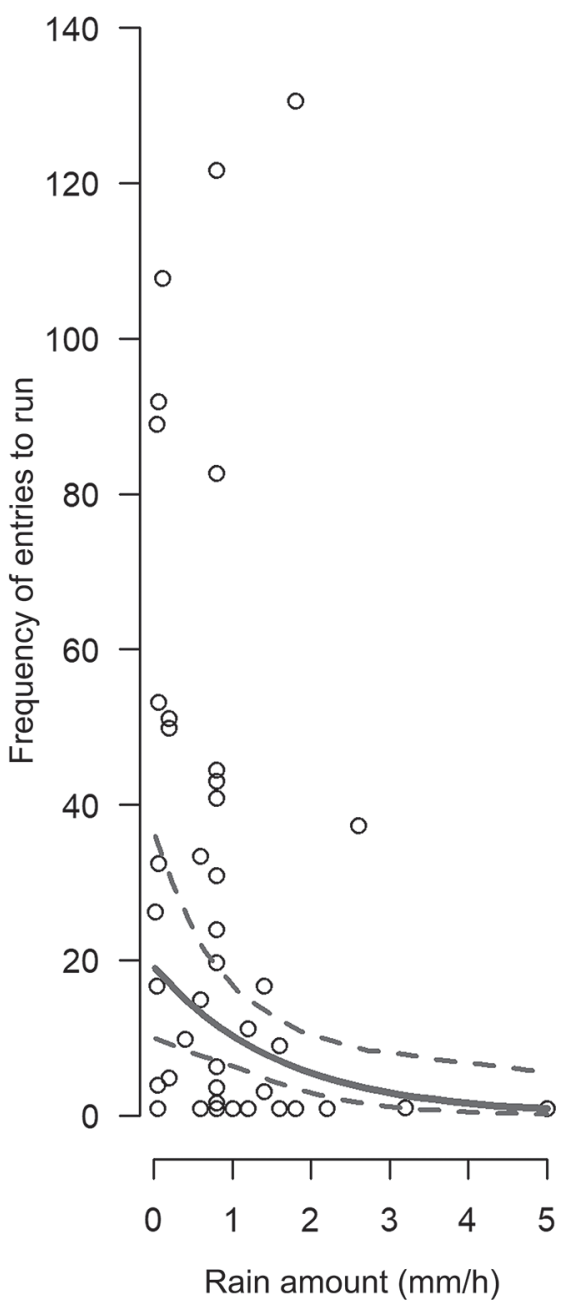

Figure 5. Frequency of entries to run in relation to day (rain/control), sequence (start of rain/end of rain), and weather (dry/rain) during

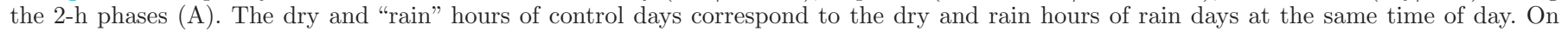

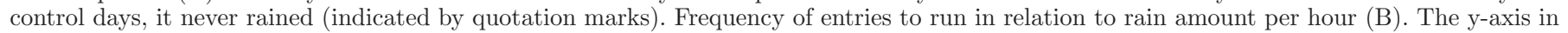

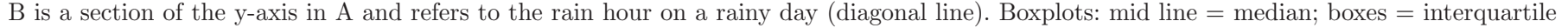
ranges; and whiskers $=$ absolute ranges. Lines: solid $=$ model estimates and dashed $=95 \%$ CI.

breeze" and "weak whiff" in human perception (Beaufort, 1805). Although our wind speed values were light to medium, we still found that wind speed reduced outdoor run use. Wind increases heat loss (Mount and Brown, 1982; McArthur, 1987) and brings the lower critical temperature up (Webster, 1974). The effect of wind is even stronger at low temperatures (McArthur, 1987). Therefore, the goats in the present study probably preferred to stay indoors under windy conditions to avoid an increased heat loss.

Our study confirms that goats react far sooner to cold than, for example, sheep do (Bøe and Ehrlenbruch, 2013). Meisfjord Jørgensen and Bøe (2011) found no difference in outdoor run use by sheep at temperatures above $0^{\circ} \mathrm{C}$ compared with temperatures below $0^{\circ} \mathrm{C}$. The high sensitivity of goats to cold is probably due to their physiological adaptations, which allow them to deal better with warmer conditions (Silanikove, 2000). In contrast to sheep, goats lack wool fleece, which provides an efficient thermal insulation (Alexander, 1974). Furthermore, due to their body size, goats have a higher surface-to-volume ratio than cattle, which facilitates a greater heat dissipation, making them more tolerant to heat but more susceptible to cold (Bergmann, 1847). The climatic conditions we measured reflect weather commonly expected on farms located in temperate cli- 
mate zones during winter. Under these conditions, installing wind breaks at exposed sites might reduce heat loss and possibly promote outdoor run use. Moreover, ensuring access to solar radiation by considering the exposure of the outdoor run to the sun might increase outdoor run use, as direct sun exposure induces warmer conditions (solar radiation being a part of "warmth"). However, further research is needed to determine the effect of wind breaks or the exposure of the outdoor run to the sun on outdoor run use.

\section{Rain}

The reduction in outdoor run use we observed during rain hours and in relation to rain amount agrees with the results of other studies. Bøe and Ehrlenbruch (2013) reported that goats used an outdoor run less during rain. Furthermore, feral goats reduce their feeding behavior in relation to rain (Brindley et al., 1989) and spend more time in caves with increasing rain amounts (Boyd, 1981). Goats' avoidance of exposure to rain can be explained by the changes in fur properties when fur gets wet. The thermal insulation capacity of wet fur is weaker compared with dry fur (Young et al., 1989). In addition, the evaporation of water from the fur increases heat loss (Alexander, 1962). Covering the outdoor run at least partially with a roof would protect the animals from rain. Indeed, Bøe and Ehrlenbruch (2013) observed that goats used the outdoor run more when a roof was provided.

In the present study, we also found that outdoor run use was, in general, lower on days with rain, during the hour before the rain began and during the hour after the rain had ended, compared with days without rain. Moreover, even a very small amount of rain $(\leq 1 \mathrm{~mm} / \mathrm{h})$ affected outdoor run use. A possible reason could be the reduced availability of dry floor surface, especially after a rain period. Goats were shown to use an outdoor run often for lying (Bøe et al., 2012; Stachowicz et al., 2018 ) and to clearly prefer lying on dry surfaces (Bøe et al., 2007). As we cannot exclude that, in the hour before the rain began on days with rain, the floor surface of the outdoor run was already wet due to a previous rain event, the reduced availability of dry floor surface could also be the reason why the outdoor run was used less during this hour. Furthermore, there might be also environmental factors that allow goats to anticipate upcoming rain, which could explain why goats began to go inside before the rain started.

As in the models for "warmth" and wind speed, the results on outdoor use in relation to rain were less clear for the variable frequency of entries to run than for proportion of herd in run. The interactive effect of sequence and weather on the frequency of entries to run showed an unexpected decrease on control days from the first to the second hour in the sequence start of rain and in the sequence end of rain. This pattern is probably linked to the characteristic of the variable frequency of entries to run. As discussed in the preceding section on CCI, "warmth," and wind speed, the variable frequency of entries to run is defined by short-term actions and therefore might depend on several factors that occur during the day in addition to weather conditions.

\section{CONCLUSIONS}

We showed that within the measured ranges of temperature $\left(-0.8\right.$ to $\left.+16.5^{\circ} \mathrm{C}\right)$, humidity (34.8 to $99.2 \%$ ), solar radiation (25.9 to $519.8 \mathrm{~W} / \mathrm{m}^{2}$ ), and wind speed ( 0 to $4 \mathrm{~m} / \mathrm{s}$ ), dairy goats use an outdoor run less if they are exposed to cold, wind, or rain. Appropriate weather protections, such as wind breaks or a roof covering the outdoor run, could therefore promote outdoor run use by dairy goats. Furthermore, ensuring access to solar radiation by considering the exposure of the outdoor run might be advantageous because direct sun exposure induces warmer conditions.

\section{ACKNOWLEDGMENTS}

Our special thanks go to all farmers who participated in this study and all colleagues of Agroscope Tänikon (Switzerland): Urs Marolf, Hans Lüthi, Markus Keller, and Hans-Rudolf Ott for their technical support; Barbara Hauser, Marion Reichenbach, Urs Marolf, and Bettina Schütz for the analysis of video recordings; and Barbara Hauser for the support in handling the goats. This project was financed by the Federal Food Safety and Veterinary Office (Project No. 2.13.11, Bern, Switzerland).

\section{REFERENCES}

Alexander, G. 1962. Temperature regulation in the new-born lamb. IV. The effect of wind and evaporation of water from the coat on metabolic rate and body temperature. Aust. J. Agric. Res. 13:82-99. https://doi.org/10.1071/AR9620082.

Alexander, G. 1974. Heat loss from sheep. Pages 187-188 in Heat Loss from Animals and Man. J. L. Monteith and L. E. Mount, ed. Butterworth, London, UK.

Andersen, I. L., and K. E. Bøe. 2007. Resting pattern and social interactions in goats-The impact of size and organisation of lying space. Appl. Anim. Behav. Sci. 108:89-103. https://doi.org/10 .1016/j.applanim.2006.10.015.

Bates, D., M. Maechler, B. Bolker, and S. Walker. 2015. Fitting linear mixed-effects models using lme4. J. Stat. Softw. 67:1-48. https:// doi.org/10.18637/jss.v067.i01.

Beaufort, F. 1805. Beaufort wind scale. Accessed Jan. 30, 2018. http:/ /www.spc.noaa.gov/faq/tornado/beaufort.html.

Bergmann, C. 1847. Über die Verhältnisse der Wärmeökonomie der Tiere zu ihrer Grösse. Vol. 3. Göttinger Studien. Vandenhoeck \& Ruprecht, Göttingen, Germany. 
Bøe, K. 1990. Thermoregulatory behaviour of sheep housed in insulated and uninsulated buildings. Appl. Anim. Behav. Sci. 27:243-252. https://doi.org/10.1016/0168-1591(90)90059-M.

Bøe, K. E., I. L. Andersen, L. Buisson, E. Simensen, and W. K. Jeksrud. 2007. Flooring preferences in dairy goats at moderate and low ambient temperature. Appl. Anim. Behav. Sci. 108:45-57. https://doi.org/10.1016/j.applanim.2006.12.002.

Bøe, K. E., and R. Ehrlenbruch. 2013. Thermoregulatory behavior of dairy goats at low temperatures and the use of outdoor yards. Can. J. Anim. Sci. 93:35-41. https://doi.org/10.4141/cjas2012-028.

Bøe, K. E., R. Ehrlenbruch, and I. L. Andersen. 2012. Outside enclosure and additional enrichment for dairy goats-A preliminary study. Acta Vet. Scand. 54:68 https://doi.org/10.1186/1751-0147 $-54-68$.

Boyd, I. L. 1981. Population changes and the distribution of a herd of feral goats (Capra sp.) on Rhum, Inner Herbrides, 1960-78. J. Zool. 193:287-304. https://doi.org/10.1111/j.1469-7998.1981 .tb03445.x.

Brindley, E. L., D. J. Bullock, and F. Maisels. 1989. Effects of rain and fly harassment on the feeding behaviour of free-ranging feral goats. Appl. Anim. Behav. Sci. 24:31-41. https://doi.org/10.1016/ 0168-1591(89)90123-8.

Canty, A., and B. Ripley. 2015. boot: bootstrap R (S-plus) functions. $\mathrm{R}$ package version 1:3-17.

Charlton, G. L., and S. M. Rutter. 2017. The behaviour of housed dairy cattle with and without pasture access: A review. Appl. Anim. Behav. Sci. 192:2-9. https://doi.org/10.1016/j.applanim .2017.05.015.

Council Regulation. 1999. Council Regulation (EC) No 1804/1999 of 19 July 1999 supplementing Regulation (EEC) No 2092/91 on organic production of agricultural products and indications referring thereto on agricultural products and foodstuffs to include livestock production. Official Journal L 222, 13:1-28. http:// www.publications.europa.eu/en/publication-detail/-/publication/ d839b766-276a-4a46-b26d-7feca84b1876/language-en.

Halekoh, U., and S. Højsgaard. 2014. A Kenward-Roger approximation and parametric bootstrap methods for tests in linear mixed models-The R package pbkrtest. J. Stat. Softw. 59:1-32. https:// doi.org/10.18637/jss.v059.i09.

Haskell, M. J., K. Masłowska, D. J. Bell, D. J. Roberts, and F. M. Langford. 2013. The effect of a view to the surroundings and microclimate variables on use of a loafing area in housed dairy cattle. Appl. Anim. Behav. Sci. 147:28-33. https://doi.org/10.1016/j .applanim.2013.04.016.

Hillmann, E., C. Mayer, and L. Schrader. 2004. Lying behaviour and adrenocortical response as indicators of the thermal tolerance of pigs of different weights. Anim. Welf. 13:329-335.

Holmes, C. W., and Y. F. Moore. 1981. Metabolizable energy required by feral goats for maintenance and the effects of cold climatic conditions on their heat production. Proc. N.Z. Soc. Anim. Prod. 41:163-166.

Johnson, K. 1971. Body temperature lability in sheep and goats during short-term exposures to heat and cold. J. Agric. Sci. 77:267-272. https://doi.org/10.1017/S0021859600024412.

Jolliffe, I. 2011. Principal component analysis. Pages 1094-1096 in International Encyclopedia of Statistical Science. M. Lovric, ed. Springer, Berlin, Heidelberg, Germany. https://doi.org/10.1007/ 978-3-642-04898-2_455.

Kadzere, C. T., M. R. Murphy, N. Silanikove, and E. Maltz. 2002. Heat stress in lactating dairy cows: A review. Livest. Prod. Sci. 77:59-91. https://doi.org/10.1016/S0301-6226(01)00330-X.
Krohn, C. C., L. Munksgaard, and B. Jonasen. 1992. Behaviour of dairy cows kept in extensive (loose housing/pasture) or intensive (tie stall) environments I. Experimental procedure, facilities, time budgets - diurnal and seasonal conditions. Appl. Anim. Behav. Sci. 34:37-47. https://doi.org/10.1016/0168-1591(94)90148-1.

$\mathrm{Lu}$, C. D. 1989. Effects of heat stress on goat production. Small Rumin. Res. 2:151-162. https://doi.org/10.1016/0921-4488(89)90040 -0 .

Mader, T. L., L. J. Johnson, and J. B. Gaughan. 2010. A comprehensive index for assessing environmental stress in animals. J. Anim. Sci. 88:2153-2165. https://doi.org/10.2527/jas.2009-2586.

McArthur, A. J. 1987. Thermal interaction between animal and microclimate: a comprehensive model. J. Theor. Biol. 126:203-238. https://doi.org/10.1016/S0022-5193(87)80229-1.

Meisfjord Jørgensen, G. H., and K. E. Bøe. 2011. Outdoor yards for sheep during winter - effects of feed location, roof and weather factors on resting and activity. Can. J. Anim. Sci. 91:213-220. https: //doi.org/10.4141/cjas10062.

Mount, L. E., and D. Brown. 1982. The use of meteorological records in estimating the effects of weather on sensible heat loss from sheep. Agric. Meteorol. 27:241-255. https://doi.org/10.1016/0002 -1571(82)90009-7.

Newberry, R. C. 1995. Environmental enrichment: increasing the biological relevance of captive environments. Appl. Anim. Behav. Sci. 44:229-243. https://doi.org/10.1016/0168-1591(95)00616-Z.

Ordinance on Direct Payments. 2013. Swiss Ordinance on Direct Payments in Agriculture SR 910.13/2013 of 23 October 2013. http: //www.admin.ch/opc/de/classified-compilation/20130216/index .html.

Organic Farming Ordinance. 2015. Ordinance on Organic Farming and the Labelling of Organically Produced Products and Foodstuffs SR 910.18/1997 of 22 September 1997. http://www.admin.ch/opc/de/ classified-compilation/19970385/index.html.

R Development Core Team. 2015. R: A Language and Environment for Statistical Computing. R Foundation for Statistical Computing, Vienna, Austria.

Silanikove, N. 2000. The physiological basis of adaptation in goats to harsh environments. Small Rumin. Res. 35:181-193. https://doi .org/10.1016/S0921-4488(99)00096-6.

Stachowicz, J., L. Gygax, E. Hillmann, B. Wechsler, and N. M. Keil. 2018. Dairy goats use outdoor runs of high quality more regardless of the quality of indoor housing. Appl. Anim. Behav. Sci. 208:2230. https://doi.org/10.1016/j.applanim.2018.08.012.

Tucker, C. B., A. R. Rogers, G. A. Verkerk, P. E. Kendall, J. R. Webster, and L. R. Matthews. 2007. Effects of shelter and body condition on the behaviour and physiology of dairy cattle in winter. Appl. Anim. Behav. Sci. 105:1-13. https://doi.org/10.1016/j applanim.2006.06.009.

van de Weerd, H. A., and J. E. L. Day. 2009. A review of environmental enrichment for pigs housed in intensive housing systems. Appl. Anim. Behav. Sci. 116:1-20. https://doi.org/10.1016/j.applanim 2008.08.001.

Webster, A. J. F. 1974. Heat loss from cattle with particular emphasis on the effects of cold. Pages 205-231 in Heat Loss from Animals and Man. J. L. Monteith and L. E. Mount, ed. Butterworth, London, UK.

Young, B. A., B. Walker, A. E. Dixon, and V. A. Walker. 1989. Physiological adaptation to the environment. J. Anim. Sci. 67:2426-2432. https://doi.org/10.2527/jas1989.6792426x. 